\title{
Follow-up of Mothers with Suspected Postpartum Depression from Pediatrics Clinics
}

\author{
Nerissa S. Bauer ${ }^{1,2 *}$, Susan Ofner ${ }^{3}$, Amy Pottenger ${ }^{1}$, Aaron E. Carroll ${ }^{2,4}$ \\ and Stephen M. Downs ${ }^{1,2}$
}

'Section of Children's Health Services Research, Pediatrics, Indiana University School of Medicine, Indianapolis, IN, United States, ${ }^{2}$ Center for Health Services Research, Regenstrief Institute, Indianapolis, IN, United States, ${ }^{3}$ Biostatistics, Indiana University School of Medicine, Indianapolis, IN, United States, ${ }^{4}$ Section of Pediatric and Adolescent Comparative Effectiveness Research, Pediatrics, Indiana University School of Medicine, Indianapolis, IN, United States

OPEN ACCESS

Edited by:

Jean Marc Guile, University of Picardie

Jules Verne, France

Reviewed by:

Andrew Leung Luk,

Nethersole Institute of

Continuing Holistic

Health Education, China

Andrew M. H. Siu,

Hong Kong Polytechnic

University, Hong Kong

Laura Nabors,

University of Cincinnati, United States

*Correspondence: Nerissa S. Bauer nsbauer@iu.edu

Specialty section:

This article was submitted

to Child Health and

Human Development,

a section of the journal

Frontiers in Pediatrics

Received: 05 July 2017 Accepted: 20 September 2017 Published: 03 October 2017

Citation:

Bauer NS, Ofner S, Pottenger A, Carroll AE and Downs SM (2017) Follow-up of Mothers with Suspected Postpartum Depression from Pediatrics Clinics.

Front. Pediatr. 5:212.

doi: 10.3389/fped.2017.00212
Purpose: Pediatric providers are increasingly screening for postpartum depression (PD), yet, it is unknown how often mothers comply with recommendations to seek treatment. The objectives were to describe the rate at which mothers with suspected PD seek treatment and explore factors that predict help-seeking behavior.

Design and methods: Mothers were recruited from four pediatric clinics after identification using the Child Health Improvement through Computer Automation ( $\mathrm{CHICA}$ ) system. Mothers with a positive screen were invited to participate in a telephone interview between January 2012 and December 2014. Mothers reported if they sought treatment or called a community resource.

Results: 73 of 133 eligible mothers participated (55\% response rate). Fifty women recalled a recommendation to seek help. Only 43.8\% (32/73) made a follow-up appointment with an adult provider and even fewer kept the appointment.

Conclusion: A majority of mothers suspected of having PD recalled a referral for further intervention; yet, less than half took action. Further investigation of barriers of helpseeking behavior is warranted.

Keywords: screening, mental health, medical home, postpartum depression, mothers

\section{INTRODUCTION}

Postpartum depression (PD) is a common and disabling mental health (MH) condition that affects approximately $15 \%$ of women after childbirth (1). Prevalence estimates are even higher among women from lower socioeconomic strata and ethnic minorities (2-4). When PD occurs, it is most common when the newborn infant is between 6 weeks and 6 months of life; however, it can occur anytime within the first year postpartum (5). Strong evidence associating PD with adverse childhood outcomes related to growth, development, and subsequent risk for $\mathrm{MH}$ and behavioral conditions supports pediatric providers' routine screening for PD and other forms of parental depression (6-10). Exposure to parental depression can also impair parenting practices, parent-child interactions, and children's functioning at home and school (11-18).

Abbreviations: PD, postpartum depression; CHICA, child health improvement through computer automation; EHR, electronic health record; PCP, primary care physician; $\mathrm{MH}$, mental health. 
To date, much of the efforts around PD within the field of pediatrics have focused on increasing pediatric providers' awareness and promoting screening in routine practice. Clinical care guidelines published by the American Academy of Pediatrics (AAP) support pediatric providers' active role in implementing surveillance and systemic screening in practice (19). Several validated and brief screening tools exist to aid providers' efforts to screen during well child visits (20-23). However, studies show that rates of screening for PD remain less than optimal (24-26). Furthermore, when mothers with depression are open to seeking help and able to access adequate $\mathrm{MH}$ treatment, children's behavior and functioning improve (27). Unlike obstetricians who can both screen and treat the mother for PD $(28,29)$, pediatric providers find themselves in a challenging position because they can identify PD, but can only facilitate getting mothers into treatment by adult providers. Moreover, women with PD historically have exhibited low rates of help seeking behavior $(30,31)$. While there have been limited studies identifying treatment-seeking behavior among identified mothers (32), there are no studies examining the moment of a positive screen and the communication that occurs between pediatric provider and the mother. There are no studies describing help-seeking rates of mothers suspected of having PD after identification by pediatric providers. It is unclear whether pediatric providers are effective in helping mothers take action concerning their own health.

The objectives of this study were twofold: (1) to describe the rate at which mothers suspected of having PD sought treatment after a positive screen occurred in a pediatric practice and (2) to explore factors associated with mothers seeking treatment. Understanding what factors are associated with mothers having a more positive attitude toward seeking treatment, such as modifiable aspects of provider-mother communication during the screening process, may help optimize the interaction between the pediatric provider and mother at the time of a positive screen.

\section{MATERIALS AND METHODS}

\section{Study Population and Design}

Participants included mothers whose children received medical care at one of the four general pediatrics clinics and were either suspected of having PD as a result of a positive screen and/or referred for an evaluation for PD at any time within the first 2 years of the child's life. Families who receive care at these clinics are largely underserved and of lower socioeconomic status who are eligible to enroll in Medicaid.

Eligible mothers were identified through the Child Health Improvement through Computer Automation (CHICA) system (33), a computer decision support system that is linked to the electronic health record and described in detail elsewhere (34-38). Briefly, CHICA is used to automate surveillance and screening of preventive care and chronic conditions based on clinical care guidelines (39-43). For PD, CHICA performs surveillance every 3 months starting at birth and up to 15 months of age (44). CHICA generates the anxiety subscale of the Edinburgh
Postpartum Depression Scale (EPDS-3), which has previously been shown to have a high sensitivity (95\%) and negative predictive value (98\%) for PD, to pre-screen families in the waiting room at the clinic (22). The EPDS-3 items focus on whether the mother blames herself unnecessarily when things go wrong, feeling scared, or panicky for no good reason, and being anxious or worried for no good reason. These items are integrated within a tailored 20-item pre-screener form that is generated based on the child's age and information contained in the $\operatorname{EHR}(45,46)$. This form is displayed electronically on a tablet that is given to the parent upon check in and is completed in the waiting room (47). If any of the EPDS-3 items is positive, CHICA generates the entire 10-item EPDS (20) to screen the mother for PD formally. Additionally, CHICA generates a handout for the provider to share with the mother. It describes PD and suggests community resources. Providers document on another CHICA-generated form, the physician worksheet, whether they suspect $P D$ and/or have referred mothers for treatment of PD after review of the EPDS. Mothers were eligible for this study if the provider marked the checkbox indicating a recommendation was made to the mother to seek additional help and/or the checkbox indicating suspected PD. During the study period, a monthly data pull of all eligible mothers was provided to the study team.

Within a few days of the data pull, eligible mothers were mailed a study information sheet and letter explaining the study and alerting her that a research assistant would call after 2 weeks to invite the mother to complete a one-time, 20-min telephone interview. Mothers could call to schedule the interview or opt out of the study. Informed consent was obtained verbally over the phone at the time of the interview, and interview questions were read in English or Spanish. If, during the interview, a mother expressed worries of harming herself or her child, an emergency protocol was initiated: the research assistant provided the mother with a phone number to call for help and the child's provider was notified immediately.

The primary objective of the study was to describe the rate at which mothers sought treatment after a positive PD screen and to explore factors that would predict mothers' help seeking behavior. "Seeking treatment" was broadly defined as a mother reporting either of the following: (1) the making an appointment with a primary care physician (PCP), obstetrician, or $\mathrm{MH}$ provider; or (2) contacting any community resource from a CHICAgenerated handout regarding $\mathrm{PD}$ and a listing of local resources.

\section{Telephone Interview Tool}

Mothers consenting to the study were asked to answer a 42 -item telephone survey. The survey included study-specific items (whether the mother remembered completing a formal screening tool for her mood, what term the provider used when talking about her mood, if she received a list of community resources to go to or call for help, whether she received recommendations to see an adult provider and if so, what type of provider, and what actions she took after the positive PD screen). Additional items came from validated tools to understand whether continuity of care and degree of family centeredness (select items from the Promoting Healthy Development Survey/PHDS (48) and degree of shared decision-making (Shared Decision-Making 
Questionnaire/SDM-Q-9) (49)) were associated with helpseeking behavior. The full-scale PHDS was shown to have strong construct validity (mean factor loading: 0.69) and internal consistency (Cronbach's $\alpha$ : 0.80) (50). The SDM-Q-9 measures the level of shared decision-making during the medical encounter and has been shown to have high internal consistency (Cronbach's $\alpha>0.9$ ) and high item discriminations for high reliability of the instrument in a primary care sample (49). Items are rated on a 6-point Likert scale from $0=$ completely disagree to $5=$ completely agree. Seven of nine items must be completed to score the scale. Items were added to calculate a raw score (0-45), which was then transformed to a range of $0-100$ by multiplying the raw score by 20/9. Higher scores indicated increased shared decision-making between pediatrician and mother. When mothers did not seek help, reasons for not taking action were asked. Sociodemographics and characteristics (first child, race and ethnicity, maternal age, highest education level, marital status, and the number of children under 18 years of age in the household) were also captured. The tool was translated into Spanish and back translated to English to assure retention of meaning.

\section{Statistical Analysis}

Demographic and other subject characteristics were summarized overall and by the primary outcome of seeking treatment (yes/no) and by the secondary outcome of the child's doctor giving the mother a recommendation for follow-up with her primary doctor, an obstetrician, or a $\mathrm{MH}$ provider. Characteristics were compared by means of chi-square and Fisher's exact test for categorical variables and by one-way analysis of variable models for continuous variables. Though the sample size was small, we decided to explore associations between outcomes and demographic characteristics (age, first child, race, Hispanic ethnicity, and marital status), the physician saying "postpartum depression," predictors of family centeredness, and shared decision-making. We fit bivariate logistic regression models with the independent variables recoded as binary with agree/disagree response categories so as to facilitate the interpretation of odds ratios. Prior to fitting multivariable logistic regression models, we assessed whether we had enough data. Using Hosmer and Lemeshow's (51) extension to multiple regression models of Peduzzi's (52) result that the number of parameters in the model should be limited by the smaller of the number of events or non-events divided by 10 , we found that we could have three variables in the primary outcome model and two variables in the secondary outcome model. We chose clinically important variables as eligible for inclusion: being a teen mother (aged $<21$ years), Hispanic, black race, other race, being married, being separated, the SDM-Q-9 composite score, and the PHDS quality score. Items from the SDM-Q-9 scale were also tested. Variables with $p$-value of 0.30 or smaller in bivariate models were selected for inclusion in a multiple regression model. Backwards variables with staying criteria of 0.10 were used to come up with final multivariable logistic regression models. To explore the relationship between the two outcomes, we fit the dependent variable of seeking treatment and independent variable of the doctor giving the mother a recommendation for follow-up. The study protocol was submitted to our institutional review board and approved prior to the initiation of study procedures. Analyses were generated using SAS/STAT software, Version 9.4 of the SAS System for Windows (copyright (C) 2002-2008 SAS Institute Inc.).

\section{RESULTS}

Of 133 mothers found to be eligible, 73 mothers agreed to participate in the telephone interview and had adequate information to be analyzed. Fifty-three women could not be reached, either due to bad phone numbers (46 women), or a refusal to participate (7 women). Only one had missing data regarding which type of adult provider was recommended, but she did report making an appointment; eight had completely missing data for "seeking treatment" and thus were excluded in the multivariable analyses. The average age among mothers was 26.8 years, with a SD of 6 years. Most of the mothers $(41 \%$ or $30 / 73)$ were African American, 21\% (15/73) white, and 8\% (6/73) mixed race. Just under half (45.2 or 33/73) were non-Hispanic. Sixty-six percent were never married and 40\% (29/73) had not completed a high school education. Approximately one-third of the mothers were identified after a positive screen with their first child. The average age of the child at the time of the telephone interview was 9.2 months, with a SD of 6 months. More than half of the women reported depressive symptoms for more than 2 weeks at a time since the child was born. Forty-eight percent (35/73) of women reported having felt sad or depressed most days for 2 years or more. These and other data are summarized in Table $\mathbf{1}$.

Approximately two-thirds of the women (50/73 or $68.5 \%$ ) reported that their pediatric providers recommended further evaluation by an adult care provider. Of those, 46 were also provided a handout with community resources. About half (36/73) took actions that were defined as "sought treatment" after the index visit, one-third $(22 / 73)$ called any type of adult provider and made an appointment, $13.7 \%(10 / 73)$ made an appointment and called any community resource from the handout, and 5.5\% (4/73) only called a community resource. An even smaller proportion of mothers actually made it to the scheduled appointment with an adult provider (37\% or $27 / 73)$. See Figure 1. Nineteen percent $(14 / 73)$ of mothers recalled only receiving a handout and $8 \%(6 / 73)$ called any of the resources listed.

Mothers had various reasons for not following through with recommendations, which included a perception that mood would improve $(n=3)$; lack of time or competing demands that necessitated mothers' assigning other duties as more important $(n=7)$ or transportation $(n=2)$. Others mentioned that they were already seeing a social worker or therapist $(n=3)$, and others reported frustration with navigating the telephone tree $(n=2)$ or expecting the call to come from the clinic $(n=1)$.

Maternal demographics did not significantly predict whether a mother received a recommendation for further help nor did they predict whether a mother ultimately took actions to seek help. Several provider behaviors were recalled significantly more often by mothers who received advice to seek further help from an adult provider as compared to mothers who did not recall this advice: provider used the term "postpartum depression" (56\% vs. $18 \%, p=0.005)$ and exhibited more of a shared decision-making style (mean SDM-Q-9 score: $66.8 \pm 24.0$ vs. $47.1 \pm 31.1, p=0.03$ ). 
TABLE 1 | Study sample characteristics.

\begin{tabular}{|c|c|c|}
\hline & & Overall \\
\hline & & $n=73$ \\
\hline \multirow[t]{3}{*}{ Age } & $N$ & 73 \\
\hline & Mean $\pm S D$ & $26.8 \pm 6.0$ \\
\hline & Median (min, max) & $25.0(17.0,44.0)$ \\
\hline \multirow[t]{3}{*}{ Hispanic or Latino origin } & Missing & 4 \\
\hline & Yes & $33(47.8)$ \\
\hline & No & $36(52.2)$ \\
\hline \multirow[t]{7}{*}{ Race } & Missing & 2 \\
\hline & White & $15(21.1)$ \\
\hline & African American & $30(42.3)$ \\
\hline & Native American & $1(1.4)$ \\
\hline & Native Hawaiian & $1(1.4)$ \\
\hline & Other & $18(25.4)$ \\
\hline & Mixed race & $6(8.5)$ \\
\hline \multirow{4}{*}{$\begin{array}{l}\text { Education: highest grade level of } \\
\text { school completed }\end{array}$} & Missing & 1 \\
\hline & Less than high school & $29(40.3)$ \\
\hline & High school & $25(34.7)$ \\
\hline & Some college & $18(25.0)$ \\
\hline \multirow[t]{3}{*}{ Marital status } & Married & $16(21.9)$ \\
\hline & Separated & 9 (12.3) \\
\hline & Never been married & $48(65.8)$ \\
\hline \multirow[t]{2}{*}{ First child } & Yes & $26(35.6)$ \\
\hline & No & $47(64.4)$ \\
\hline \multirow[t]{3}{*}{ Childs age (in months) } & $\mathrm{N}$ & 73 \\
\hline & Mean \pm SD & $9.2 \pm 6.0$ \\
\hline & Median (min, max) & $9.0(1.0,24.0)$ \\
\hline \multirow{2}{*}{$\begin{array}{l}\text { Felt sad, blue, or depressed for } \\
2 \text { weeks or more since child was born }\end{array}$} & Yes & $40(54.8)$ \\
\hline & No & $33(45.2)$ \\
\hline \multirow{2}{*}{$\begin{array}{l}\text { Had } 2 \text { or more years when felt } \\
\text { depressed or sad most days }\end{array}$} & Yes & $35(47.9)$ \\
\hline & No & $38(52.1)$ \\
\hline
\end{tabular}

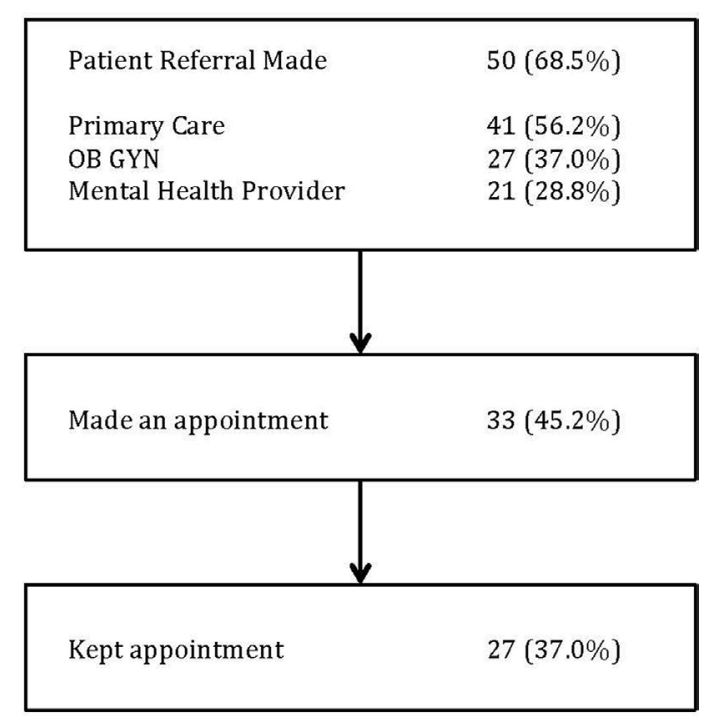

*Some mothers may have reported more than 1 referral

FIGURE 1 | Actions taken by mothers after a positive PD screen $(N=73)^{*}$. *Some mothers may have reported more than one referral.
More specifically, the behaviors that were significant were: the provider made explicit that a decision needed to be made about her health $(p<0.0001)$, explained that there were different options for treatment of her mood $(p=0.004)$, and provided explanation of the advantages and disadvantages of each $(p=0.01)$. See Table 2.

\section{DISCUSSION}

A majority of women suspected of having PD after an initial positive screen in the pediatric office recalled a discussion with the pediatric provider about the need to seek follow-up with an adult provider. However, successively smaller proportions of those mothers took steps to seek treatment for themselves. Maternal demographics did not predict whether mothers recalled receiving a recommendation for further treatment when the pediatric provider shared the results of screening or in eventually seeking treatment.

While it is known many mothers with PD do not seek help, our study is the first to examine what happens after a positive PD screen. The number of pediatric providers screening for PD are increasing (53); however, our study highlights that sharing the results of screening and what is communicated to the mother can impact whether she seeks help. Our study also suggests a shared decision-making approach may be helpful in getting mothers to consider taking action. In particular, explaining what treatment options are available and the benefits and disadvantages of each in the context of the importance of seeking help. Our work complements studies examining communication factors and preferences for depression advice within obstetrics and gynecology clinics examining management after a positive screen $(54,55)$. However, while provider communication can be modified, it is clear that more work is needed in examining additional methods to get mothers linked to active treatment. Closer examination of maternal barriers should include the influence of personally held beliefs and attitudes, cultural and societal norms, and access to resources. In a qualitative study by Sword et al., mothers described discomfort with discussing $\mathrm{MH}$ concerns, fears, and deciding to wait for symptom improvement as reasons to defer care (56). Mothers with limited understanding of PD or who had friends or family who normalized symptoms were less likely to seek treatment $(56,57)$. In yet another study among underserved Hispanic women, only half of the women with a positive $\mathrm{PD}$ screen recognized a need to seek help for depression (58). Tailoring health messages about signs and symptoms of PD for at-risk women is a necessary component of future interventions; otherwise, it would be difficult to mobilize women to seek treatment if they lacked insight into the need for it. Furthermore, mothers may fear that disclosing symptoms will lead to child protective services involvement (59). Women in our sample endorsed perceptions that their mood would improve with time, along with resource or material barriers, such as lack of time and childcare issues or difficulty with navigating the telephone appointment system, which have been also been reported as barriers to help seeking in other studies (60). Alternatively, facilitators of help-seeking behaviors should also be considered. 
TABLE 2 | Bivariate summaries and odds ratios for mothers who recalled recommendation for treatment.

\begin{tabular}{|c|c|c|c|c|c|c|c|c|c|}
\hline & & \multicolumn{4}{|c|}{ Recommendation } & \multicolumn{4}{|c|}{ Sought treatment } \\
\hline & & \multirow{2}{*}{$\frac{\text { Yes }}{50(69.44 \%)}$} & \multirow{2}{*}{$\frac{\text { No }}{22(30.56 \%)}$} & \multirow[t]{2}{*}{$p$-Value } & \multirow{2}{*}{$\begin{array}{c}\text { Odds ratio (95\% } \\
\text { confidence interval) }\end{array}$} & \multirow{2}{*}{$\frac{\text { Yes }}{42(64.6 \%)}$} & \multirow{2}{*}{$\frac{\text { No }}{23(35.4 \%)}$} & \multirow[t]{2}{*}{$p$-Value } & \multirow{2}{*}{$\begin{array}{c}\text { Odds ratio ( } 95 \% \\
\text { confidence interval) }\end{array}$} \\
\hline & & & & & & & & & \\
\hline Age $<21$ & & $6(12.0)$ & $4(18.2)$ & 0.4875 & $0.61(0.16,2.44)$ & $7(16.7)$ & $3(13.0)$ & 0.6993 & $1.33(0.31,5.74)$ \\
\hline First child & & $16(32.0)$ & $9(40.9)$ & 0.4656 & $0.68(0.24,1.92)$ & $14(33.3)$ & $10(43.5)$ & 0.4189 & $0.65(0.23,1.85)$ \\
\hline Hispanic & & $24(49.0)$ & $9(47.4)$ & 0.9051 & $1.07(0.37,3.08)$ & $19(47.5)$ & $9(40.9)$ & 0.6182 & $1.31(0.46,3.74)$ \\
\hline \multirow[t]{3}{*}{ Race } & Black & 19 (39.6) & $10(45.5)$ & 0.7186 & $1.27(0.35,4.58)$ & $17(41.5)$ & $10(45.5)$ & 0.9335 & $0.94(0.25,3.62)$ \\
\hline & Other & $20(41.7)$ & $6(27.3)$ & 0.2561 & $2.22(0.56,8.82)$ & $15(36.6)$ & $7(31.8)$ & 0.8091 & $1.19(0.29,4.90)$ \\
\hline & White & $9(18.8)$ & $6(27.3)$ & & Reference & $9(22.0)$ & $5(22.7)$ & & Reference \\
\hline \multirow[t]{3}{*}{ Marital status } & Married & $11(22.0)$ & $5(22.7)$ & 0.9606 & $1.03(0.30,3.50)$ & $7(16.7)$ & $8(34.8)$ & 0.0905 & $0.35(0.10,1.18)$ \\
\hline & Separated & $7(14.0)$ & $2(9.1)$ & 0.5654 & $1.64(0.30,8.86)$ & 5 (11.9) & $3(13.0)$ & 0.6151 & $0.67(0.14,3.24)$ \\
\hline & $\begin{array}{l}\text { Never been } \\
\text { married }\end{array}$ & $32(64.0)$ & $15(68.2)$ & & & $30(71.4)$ & $12(52.2)$ & & Reference \\
\hline \multicolumn{2}{|c|}{$\begin{array}{l}\text { Felt sad, blue, or depressed } \\
\text { for } 2 \text { weeks or more since } \\
\text { child was born }\end{array}$} & $29(58.0)$ & $11(50.0)$ & 0.5298 & $1.38(0.51,3.78)$ & $24(57.1)$ & $11(47.8)$ & 0.4721 & $1.46(0.52,4.04)$ \\
\hline \multicolumn{2}{|c|}{$\begin{array}{l}\text { Child's doctor said } \\
\text { "postpartum depression" }\end{array}$} & $28(56.0)$ & $4(18.2)$ & 0.0050 & $5.73(1.69,19.37)$ & $23(54.8)$ & $8(34.8)$ & 0.1265 & $2.27(0.79,6.50)$ \\
\hline PHDS quality & Mean $\pm S D$ & $92.9 \pm 20.8$ & $93.2 \pm 19.7$ & 0.9620 & $1.00^{\mathrm{a}}(0.88,1.13)$ & $95.6 \pm 16.6$ & $92.8 \pm 21.8$ & 0.5630 & $1.04^{\mathrm{a}}(0.91,1.19)$ \\
\hline SDM9 composite & Mean $\pm \mathrm{SD}$ & $66.8 \pm 24.0$ & $47.1 \pm 31.1$ & 0.0272 & $1.15(1.02,1.29)$ & $68.0 \pm 25.6$ & $61.9 \pm 24.7$ & 0.4197 & $1.05^{\mathrm{a}}(0.94,1.18)$ \\
\hline \multicolumn{2}{|c|}{$\begin{array}{l}\text { Make it clear that a decision } \\
\text { about mother's health needs } \\
\text { to be made }\end{array}$} & $44(89.8)$ & $4(30.8)$ & 0.0001 & $19.80(4.43,88.52)$ & $34(85.0)$ & $14(77.8)$ & 0.5029 & $1.62(0.40,6.63)$ \\
\hline \multicolumn{2}{|c|}{$\begin{array}{l}\text { Asks how mother wants to be } \\
\text { involved in decision-making }\end{array}$} & $41(87.2)$ & $9(64.3)$ & 0.0598 & $3.80(0.95,15.23)$ & $35(92.1)$ & $15(75.0)$ & 0.0867 & $3.89(0.82,18.39)$ \\
\hline \multicolumn{2}{|c|}{$\begin{array}{l}\text { Explains different options for } \\
\text { treating mother's mood }\end{array}$} & $42(89.4)$ & $8(53.3)$ & 0.0044 & $7.35(1.86,29.05)$ & $35(87.5)$ & 15 (83.3) & 0.6713 & $1.40(0.30,6.62)$ \\
\hline \multicolumn{2}{|c|}{$\begin{array}{l}\text { Explains advantages or } \\
\text { disadvantages of the } \\
\text { treatment options }\end{array}$} & $30(69.8)$ & 5 (31.3) & 0.0103 & $5.08(1.47,17.57)$ & $26(70.3)$ & $10(58.8)$ & 0.4092 & $1.66(0.50,5.47)$ \\
\hline \multicolumn{2}{|c|}{$\begin{array}{l}\text { Helps her understand all } \\
\text { the information }\end{array}$} & $44(93.6)$ & $15(78.9)$ & 0.0964 & $3.91(0.78,19.52)$ & $37(92.5)$ & $19(90.5)$ & 0.7847 & $1.30(0.20,8.45)$ \\
\hline \multicolumn{2}{|c|}{$\begin{array}{l}\text { Together choses treatment } \\
\text { option }\end{array}$} & $27(62.8)$ & $7(50.0)$ & 0.3992 & $1.69(0.50,5.70)$ & $22(64.7)$ & $12(66.7)$ & 0.8876 & $0.92(0.27,3.06)$ \\
\hline \multicolumn{2}{|c|}{$\begin{array}{l}\text { Agrees with her on how } \\
\text { to get help }\end{array}$} & $34(77.3)$ & $9(50.0)$ & 0.039 & $3.40(1.06,10.87)$ & $28(77.8)$ & $14(66.7)$ & 0.3608 & $1.75(0.53,5.81)$ \\
\hline
\end{tabular}

${ }^{a}$ For $5 \%$ increase. Multivariable modeling of help-seeking behavior resulted in only one statistically significant explanatory variable; namely, if the mother reported the provider simply having the discussion after a positive screen (72 vs. 22.7\%; AOR: 4.63; 95\% Cl: 1.32-16.24).

Significance of bold font are results that are statistically significant and for ease of review.

Among women seen in a hospital-based obstetrics and gynecology clinic, factors associated with help seeking included if the mother identified the obstetrician/gynecologist as their primary care provider, had previously used $\mathrm{MH}$ care, had at least one chronic health condition, or had high depressive symptoms (55). Thus, the development of primary care-based interventions should strive to take into account the myriad of intrinsic barriers, as well as facilitators toward seeking care in order to be effective. It also raises the need for pediatricians to partner with and include the help of pediatric nurse practitioners, nurses, and social workers in the pediatric medical home at the time a positive screen occurs.

Pediatricians' attitudes and practices around screening for PD are additional targets for optimizing outcomes for mothers suspected of PD (25). Pediatricians who rely solely upon observational cues may under-identify mothers at-risk for PD $(61,62)$. Additionally, studies have uncovered differences in providers' and women's cues to identify depression (58). Further, the course of depressive symptoms across the first year postpartum has high variability (63). It is likely that screening done only once in the postnatal period may not be enough to detect women whose symptoms persist beyond the first 3 months or develop later. Currently, the AAP encourages pediatricians to screen at the 1, 2, 4, and 6-month well child visits (19); however, data suggest that adherence to recommended screening guidelines is low $(53,64)$. Similar efforts to boost pediatricians screening around developmental delays, including clinical care guidelines for developmental screening during well child visits have yielded improvements in clinicians' screening rates, but remain less than optimal (65). Thus, integrating innovative ways to increase 
systems-level screening, such as through automation and health information technology as we have done with our work using CHICA (41) should be ongoing.

The index visit where a positive PD screen occurs should be viewed as a "teachable moment." This study suggests that if the pediatric provider employs effective communication strategies, it may facilitate help-seeking behavior from mothers suspected of having PD. While communication factors are broad, in one study among Latino immigrants, simply having someone (such as a family member, friend, neighbor, minister) alert them to having an emotional problem was associated with help seeking (66). Although more studies are needed to elucidate mechanisms underlying communication and health outcomes, one review suggested that women who feel comfortable with and have an established relationship with a primary care provider, coupled with ensuring patient understanding, trust, and clinician-patient agreement may lead to adherence and better self-care skills (67). However, known provider-level barriers include lack of training, low self-confidence on how to begin the conversation, what potential actions to take based on mothers' depression severity, or where to refer in the event of a positive screen (68). The use of practical and high yield communication strategies to handle sensitive, psychosocial topics in primary care, such as the common factors approach (69) or motivational interviewing, may allow the pediatrician to capitalize upon the "teachable moment" and spur mothers to seek help (70). Yet, modifying provider communication may not be enough and more multimodal strategies are needed. Stepped care or medical home models to foster collaboration between pediatricians and co-located $\mathrm{MH}$ providers may improve access to treatment rates for mothers with suspected PD $(71,72)$. While not limited to PD, the "Motivating Our Mothers (MOM) pilot" consisted of screening mothers of children 0-12 years of age for depression during well child visits and providing mothers with written and verbal targeted depression education and motivational messages for help-seeking (73). However, more work is needed to examine whether providers' communication styles and practice models ultimately lead to improved outcomes through activation of mothers to seek help or other mechanisms.

As with all studies, there are inherent limitations in this work that warrant consideration. First, this was an observational study comprised of a small sample recruited from community clinics in the Midwest. Of 133 eligible women, 73 consented to complete the interview, for a participation rate of 55\%. As per our usual study protocol, each eligible subject receives an average of three contact attempts (range 1-10). Therefore, participation was limited by the use of a convenience sample from those reached by phone, which may bias results. Moreover, state-level and institutional policies may have influenced practice patterns related to screening, and thus our results may not be generalizable in other areas. Second, we relied upon maternal report of events, which are subject both to social desirability and recall bias. Some might argue that mothers did not actually seek treatment based on our definition; however, it is important to understand what steps mothers take to help themselves. In this study, the measurement of seeking treatment was either calling to make an appointment or calling a community resource; however, in order to impact outcomes, mothers who actually keep appointments and engage with $\mathrm{MH}$ are more likely to have improvements that impact outcomes (27). It is encouraging that among the mothers who reported making an appointment, a high proportion of them actually reported attending the appointment. This is similar to other work with Chinese adults with $\mathrm{MH}$ problems that showed intention and behavior change are correlated (74). Similarly, willingness to seek professional help for a serious emotional problem and feeling comfortable talking about personal problems have also been shown to be associated with future help seeking and treatment use from a large cohort of respondents in the US National Comorbidity Survey (75). Therefore, using the teachable moment to raise mothers' intention to seek help may be powerful. Understanding each step toward getting mothers to access treatment identifies potential targets for intervention that may ultimately improve the pediatric medical home to support mothers and their infants. Last, our study included mothers who were screened based upon CHICA's clinical care algorithm, which includes PD screening through 15 months of age. While the age range extends screening beyond the recommended first 6 months of life (19), studies have shown that while a majority of PD occurs within the first 3 months post-delivery, some women may continue to develop symptoms of PD through the first year $(76,77)$. Mothers with a prior history of PD or major depression are at highest risk for recurring symptoms in the first year (78). Moreover, the decision to screen for an additional 3 months beyond 1 year was because our families may not always make it to the clinic for the 12-month well-child visit. The choice to increase the age range at which CHICA automatically screens were thus intended serve as a safety net.

\section{CONCLUSION}

Postpartum depression is common. Pediatric providers acknowledge that there is a need to screen and identify mothers at-risk as untreated PD leads to negative outcomes for the child and parent-child dyad. Mothers who receive clear communication from the providers about suspected PD and the need to seek treatment from an adult provider are more likely to take the first step toward getting help. However, more work is needed to tailor interventions to take into account the systems-level and maternal-level barriers likely contributing to mothers currently not seeking treatment.

\section{ETHICS STATEMENT}

This study was carried out in accordance with the recommendations of our institutional review board and approved prior to the initiation of study procedures. Subjects were consented by telephone and were mailed a copy of the study information sheet and informed consent document as approved by our institutional review board.

\section{AUTHOR CONTRIBUTIONS}

NB is the first author and responsible for the conception and design, analysis, and interpretation of the data. NB developed the telephone interview and script, emergency protocols, and 
trained the research assistants. She drafted the article and revised it critically with the input of co-authors and other individuals who agreed to read early versions of the manuscript. SO is a biostatistician who completed the data analysis and worked with NB on interpretation of final results. She is a co-author who helped with the initial draft of the statistical methods and results section and helped with the revision of the entire manuscript prior to submission. AP is a research assistant and lead study coordinator for the project. She oversaw study protocol implementation, assisted NB with human subjects, conducted telephone interviews, and involved with data collection and data entry. She conducted a literature review and revised the manuscript prior to submission. AC is a co-author who helped with the revision of the entire manuscript. SD is a co-author and has provided

\section{REFERENCES}

1. Wisner KL, Parry BL, Piontek CM. Clinical practice. Postpartum depression. N Engl J Med (2002) 347(3):194-9. doi:10.1056/NEJMcp011542

2. Chaudron LH, Kitzman HJ, Peifer KL, Morrow S, Perez LM, Newman MC. Prevalence of maternal depressive symptoms in low-income Hispanic women. JClin Psychiatry (2005) 66(4):418-23. doi:10.4088/JCP. v66n0402

3. Kozhimannil KB, Trinacty CM, Busch AB, Huskamp HA, Adams AS. Racial and ethnic disparities in postpartum depression care among low-income women. Psychiatr Serv (2011) 62(6):619-25. doi:10.1176/appi. ps.62.6.619

4. Sterling B, Fowles E, Kim S, Latimer L, Walker LO. Ethnic-specific perceptions of altered control among American women: implications for health promotion programs after pregnancy. Health Care Women Int (2011) 32(1):39-56. doi:10.1080/07399332.2010.529353

5. Gavin NI, Gaynes BN, Lohr KN, Meltzer-Brody S, Gartlehner G, Swinson T. Perinatal depression: a systematic review of prevalence and incidence. Obstet Gynecol (2005) 106(5 Pt 1):1071-83. doi:10.1097/01. AOG.0000183597.31630.db

6. Avan B, Richter LM, Ramchandani PG, Norris SA, Stein A. Maternal postnatal depression and children's growth and behaviour during the early years of life: exploring the interaction between physical and mental health. Arch Dis Child (2010) 95(9):690-5. doi:10.1136/adc.2009.164848

7. Field T. Prenatal depression effects on early development: a review. Infant Behav Dev (2011) 34(1):1-14. doi:10.1016/j.infbeh.2010.09.008

8. Gress-Smith JL, Luecken LJ, Lemery-Chalfant K, Howe R. Postpartum depression prevalence and impact on infant health, weight, and sleep in low-income and ethnic minority women and infants. Matern Child Health $J$ (2012) 16(4):887-93. doi:10.1007/s10995-011-0812-y

9. Speranza AM, Ammaniti M, Trentini C. An overview of maternal depression, infant reactions, and intervention programmes. Clin Neuropsychiatry (2006) 3(1):57-68.

10. Verbeek T, Bockting CL, van Pampus MG, Ormel J, Meijer JL, Hartman CA, et al. Postpartum depression predicts offspring mental health problems in adolescence independently of parental lifetime psychopathology. J Affect Disord (2012) 136(3):948-54. doi:10.1016/j.jad.2011.08.035

11. Barker ED, Jaffee SR, Uher R, Maughan B. The contribution of prenatal and postnatal maternal anxiety and depression to child maladjustment. Depress Anxiety (2011) 28(8):696-702. doi:10.1002/da.20856

12. Bauer NS, Gilbert AL, Carroll AE, Downs SM. Associations of early exposure to intimate partner violence and parental depression with subsequent mental health outcomes. JAMA Pediatr (2013) 167(4):341-7. doi:10.1001/ jamapediatrics.2013.780

13. Chaudron LH. Postpartum depression: what pediatricians need to know. Pediatr Rev (2003) 24(5):154-61. doi:10.1542/pir.24-5-154

14. Essex MJ, Klein MH, Miech R, Smider NA. Timing of initial exposure to maternal major depression and children's mental health symptoms in kindergarten. Br J Psychiatry (2001) 179:151-6. doi:10.1192/bjp.179.2.151 mentoring and support to NB, provided input into study design, and revised paper.

\section{FUNDING}

Internal grant funding made this study possible from the Indiana University School of Medicine Biomedical Research Committee. $\mathrm{NB}$ is an investigator with the Implementation Research Institute (IRI) at the George Warren Brown School of Social Work, Washington University in St. Louis; through an award from the National Institute of Mental Health (5R25MH08091607) and the Department of Veteran Affairs, Health Services Research \& Developmental Service, Quality Enhancement Research Initiative (QUERI).

15. Gilbert AL, Bauer NS, Carroll AE, Downs SM. Child exposure to parental violence and psychological distress associated with delayed milestones. Pediatrics (2013) 132(6):e1577-83. doi:10.1542/peds.2013-1020

16. Kavanaugh M, Halterman JS, Montes G, Epstein M, Hightower AD, Weitzman M. Maternal depressive symptoms are adversely associated with prevention practices and parenting behaviors for preschool children. Ambul Pediatr (2006) 6(1):32-7. doi:10.1016/j.ambp.2005.09.002

17. LaRosa AC, Glascoe FP, Macias MM. Parental depressive symptoms: relationship to child development, parenting, health, and results on parentreported screening tools. J Pediatr (2009) 155(1):124-8. doi:10.1016/j. jpeds.2009.02.028

18. Silverstein M, Augustyn M, Cabral H, Zuckerman B. Maternal depression and violence exposure: double jeopardy for child school functioning. Pediatrics (2006) 118(3):e792-800. doi:10.1542/peds.2005-1841

19. Earls MF. Incorporating recognition and management of perinatal and postpartum depression into pediatric practice. Pediatrics (2010) 126(5): 1032-9. doi:10.1542/peds.2010-2348

20. Cox JL, Holden JM, Sagovsky R. Detection of postnatal depression. Development of the 10-item Edinburgh Postnatal Depression Scale. Br J Psychiatry (1987) 150:782-6. doi:10.1192/bjp.150.6.782

21. Gjerdingen D, Crow S, McGovern P, Miner M, Center B. Postpartum depression screening at well-child visits: validity of a 2-question screen and the PHQ-9. Ann Fam Med (2009) 7(1):63-70. doi:10.1370/afm.933

22. Kabir K, Sheeder J, Kelly LS. Identifying postpartum depression: are 3 questions as good as 10? Pediatrics (2008) 122(3):e696-702. doi:10.1542/ peds.2007-1759

23. Kroenke K, Spitzer RL, Williams JB. The PHQ-9: validity of a brief depression severity measure. JGen Intern Med (2001) 16(9):606-13. doi:10.1046/j. 1525-1497.2001.016009606.x

24. Connelly CD, Baker MJ, Hazen AL, Mueggenborg MG. Pediatric health care providers' self-reported practices in recognizing and treating maternal depression. Pediatr Nurs (2007) 33(2):165-72, 27.

25. Olson AL, Kemper KJ, Kelleher KJ, Hammond CS, Zuckerman BS, Dietrich AJ. Primary care pediatricians' roles and perceived responsibilities in the identification and management of maternal depression. Pediatrics (2002) 110(6):1169-76. doi:10.1542/peds.110.6.1169

26. Psaros C, Geller PA, Sciscione AC, Bonacquisti A. Screening practices for postpartum depression among various health care providers. J Reprod Med (2010) 55(11-12):477-84.

27. Pilowsky DJ, Wickramaratne P, Talati A, Tang M, Hughes CW, Garber J, et al. Children of depressed mothers 1 year after the initiation of maternal treatment: findings from the STAR ${ }^{\star D}$-Child Study. Am J Psychiatry (2008) 165(9):1136-47. doi:10.1176/appi.ajp.2008.07081286

28. Evins GG, Theofrastous JP, Galvin SL. Postpartum depression: a comparison of screening and routine clinical evaluation. Am J Obstet Gynecol (2000) 182(5):1080-2. doi:10.1067/mob.2000.105409

29. Fergerson SS, Jamieson DJ, Lindsay M. Diagnosing postpartum depression: can we do better? Am J Obstet Gynecol (2002) 186(5):899-902. doi:10.1067/ mob.2002.123404 
30. McGarry J, Kim H, Sheng X, Egger M, Baksh L. Postpartum depression and help-seeking behavior. J Midwifery Womens Health (2009) 54(1):50-6. doi:10.1016/j.jmwh.2008.07.003

31. Broadhurst K. Engaging parents and carers with family support services: what can be learned from research on help-seeking? Child Fam Soc Work (2003) 8:341-50. doi:10.1046/j.1365-2206.2003.00289.x

32. Liberto TL. Screening for depression and help-seeking in postpartum women during well-baby pediatric visits: an integrated review. J Pediatr Health Care (2012) 26(2):109-17. doi:10.1016/j.pedhc.2010.06.012

33. Anand V, Biondich PG, Liu G, Rosenman M, Downs SM. Child health improvement through computer automation: the CHICA system. Stud Health Technol Inform (2004) 107(Pt 1):187-91. doi:10.3233/978-1-60750-9493-187

34. Biondich PG, Downs SM, Anand V, Carroll AE. Automating the recognition and prioritization of needed preventive services: early results from the CHICA system. AMIA Annu Symp Proc (2005):51-5.

35. Biondich PG, Overhage JM, Dexter PR, Downs SM, Lemmon L, McDonald CJ. A modern optical character recognition system in a real world clinical setting: some accuracy and feasibility observations. Proc AMIA Symp (2002):56-60.

36. Biondich PG, Anand V, Downs SM, McDonald CJ. Using adaptive turnaround documents to electronically acquire structured data in clinical settings. AMIA Annu Symp Proc (2003):86-90.

37. Anand V, Biondich P, Carroll AE, Downs SM. Tailoring interface for Spanish language: a case study with CHICA system. Hum Cent Des (2009) 5619:398-407. doi:10.1007/978-3-642-02806-9_46

38. Downs SM, Anand V, Sheley M, Grannis SJ. The last mile: using fax machines to exchange data between clinicians and public health. Online JPublic Health Inform (2011) 3(3):1-14. doi:10.5210/ojphi.v3i3.3892

39. Carroll AE, Biondich PG, Anand V, Dugan TM, Sheley ME, Xu SZ, et al. Targeted screening for pediatric conditions with the CHICA system. JAm Med Inform Assoc (2011) 18(4):485-90. doi:10.1136/amiajnl-2011000088

40. Bauer NS, Sturm LA, Carroll AE, Downs SM. Computer decision support to improve autism screening and care in community pediatric clinics. Infants Young Child (2013) 26(4):306-17. doi:10.1097/IYC.0b013e3182a4ec5e

41. Carroll AE, Bauer NS, Dugan TM, Anand V, Saha C, Downs SM. Use of a computerized decision aid for ADHD diagnosis: a randomized controlled trial. Pediatrics (2013) 132(3):e623-9. doi:10.1542/peds.2013-0933

42. Carroll AE, Bauer NS, Dugan TM, Anand V, Saha C, Downs SM. Use of a computerized decision aid for developmental surveillance and screening: a randomized clinical trial. JAMA Pediatr (2014) 168(9):815-21. doi:10.1001/ jamapediatrics.2014.464

43. Downs SM, Zhu V, Anand V, Biondich PG, Carroll AE. The CHICA smoking cessation system. AMIA Annu Symp Proc (2008) 2008:166-70.

44. Carroll AE, Biondich P, Anand V, Dugan TM, Downs SM. A randomized controlled trial of screening for maternal depression with a clinical decision support system. J Am Med Inform Assoc (2013) 20(2):311-6. doi:10.1136/amiajnl-2011000682

45. Downs SM, Biondich PG, Anand V, Zore M, Carroll AE. Using Arden Syntax and adaptive turnaround documents to evaluate clinical guidelines. AMIA Annu Symp Proc (2006):214-8.

46. Downs SM, Uner H. Expected value prioritization of prompts and reminders. Proc AMIA Symp (2002):215-9.

47. Anand V, McKee SJ, Dugan TM, Downs SM. Leveraging electronic tablets for general pediatric care: a pilot study. Appl Clin Inform (2015) 6(1):15. doi:10.4338/ACI-2014-09-RA-0071

48. Bethell C, Reuland C, Latzke B. The Promoting Healthy Development Survey (PHDS-PLUS): Implementation Guidelines for Medicaid and Other Settings. The Commonwealth Fund (2005).

49. Kriston L, Scholl I, Holzel L, Simon D, Loh A, Harter M. The 9-item shared decision making questionnaire (SDM-Q-9). Development and psychometric properties in a primary care sample. Patient Educ Couns (2010) 80(1):94-9. doi:10.1016/j.pec.2009.09.034

50. Bethell C, Peck C, Schor E. Assessing health system provision of well-child care: the promoting healthy development survey. Pediatrics (2001) 107(5): 1084-94. doi:10.1542/peds.107.5.1084

51. Hosmer DW, Lemeshow S. Applied Logistic Regression, Second Edition. New York: John Wiley \& Son, Inc (2000).
52. Peduzzi P, Concato J, Kemper E, Holford TR, Feinstein AR. A simulation study of the number of events per variable in logistic regression analysis. J Clin Epidemiol (1996) 49(12):1373-9. doi:10.1016/S0895-4356(96) 00236-3

53. Kerker BD, Storfer-Isser A, Stein RE, Garner A, Szilagyi M, O’Connor KG, et al. Identifying maternal depression in pediatric primary care: changes over a decade. JDev Behav Pediatr (2016) 37(2):113-20. doi:10.1097/ DBP.0000000000000255

54. Scholle SH, Kelleher K. Assessing primary care performance in an obstetrics/gynecology clinic. Women Health (2003) 37(1):15-30. doi:10.1300/ J013v37n01_02

55. Scholle SH, Kelleher K. Preferences for depression advice among lowincome women. Matern Child Health J (2003) 7(2):95-102. doi:10.1023/A: 1023864810207

56. Sword W, Busser D, Ganann R, McMillan T, Swinton M. Women's careseeking experiences after referral for postpartum depression. Qual Health Res (2008) 18(9):1161-73. doi:10.1177/1049732308321736

57. Dennis CL, Chung-Lee L. Postpartum depression help-seeking barriers and maternal treatment preferences: a qualitative systematic review. Birth (2006) 33(4):323-31. doi:10.1111/j.1523-536X.2006.00130.x

58. Chaudron LH, Kitzman HJ, Peifer KL, Morrow S, Perez LM, Newman MC. Self-recognition of and provider response to maternal depressive symptoms in low-income Hispanic women. J Womens Health (2005) 14(4):331-8. doi:10.1089/jwh.2005.14.331

59. Feinberg E, Smith MV, Naik R. Ethnically diverse mothers' views on the acceptability of screening for maternal depressive symptoms during pediatric well-child visits. J Health Care Poor Underserved (2009) 20(3):780-97. doi:10.1353/hpu.0.0169

60. Goodman JH. Women's attitudes, preferences, and perceived barriers to treatment for perinatal depression. Birth (2009) 36(1):60-9. doi:10.1111/j.1523536X.2008.00296.x

61. Heneghan AM, Chaudron LH, Storfer-Isser A, Park ER, Kelleher KJ, Stein RE, et al. Factors associated with identification and management of maternal depression by pediatricians. Pediatrics (2007) 119(3):444-54. doi:10.1542/peds.2006-0765

62. Heneghan AM, Silver EJ, Bauman LJ, Stein RE. Do pediatricians recognize mothers with depressive symptoms? Pediatrics (2000) 106(6):1367-73. doi:10.1542/peds.106.6.1367

63. Chaudron LH, Kitzman HJ, Szilagyi PG, Sidora-Arcoleo K, Anson E. Changes in maternal depressive symptoms across the postpartum year at well child care visits. Ambul Pediatr (2006) 6(4):221-4. doi:10.1016/j.ambp. 2006.04.003

64. Leiferman JA, Dauber SE, Heisler K, Paulson JF. Primary care physicians' beliefs and practices toward maternal depression. J Womens Health (2008) 17(7):1143-50. doi:10.1089/jwh.2007.0543

65. Radecki L, Sand-Loud N, O'Connor KG, Sharp S, Olson LM. Trends in the use of standardized tools for developmental screening in early childhood: 2002-2009. Pediatrics (2011) 128(1):14-9. doi:10.1542/peds. 2010-2180

66. Caplan S, Buyske S. Depression, help-seeking and self-recognition of depression among Dominican, Ecuadorian and Colombian immigrant primary care patients in the northeastern United States. Int J Environ Res Public Health (2015) 12(9):10450-74. doi:10.3390/ijerph120910450

67. Street RL Jr, Makoul G, Arora NK, Epstein RM. How does communication heal? Pathways linking clinician-patient communication to health outcomes. Patient Educ Couns (2009) 74(3):295-301. doi:10.1016/j.pec.2008. 11.015

68. Wissow LS, Roter DL, Wilson ME. Pediatrician interview style and mothers' disclosure of psychosocial issues. Pediatrics (1994) 93(2):289-95.

69. Wissow LS, Gadomski A, Roter D, Larson S, Brown J, Zachary C, et al. Improving child and parent mental health in primary care: a clusterrandomized trial of communication skills training. Pediatrics (2008) 121: 266-75. doi:10.1542/peds.2007-0418

70. Wissow LS, Larson S, Anderson J, Hadjiisky E. Pediatric residents' responses that discourage discussion of psychosocial problems in primary care. Pediatrics (2005) 115(6):1569-78. doi:10.1542/peds.2004-1535

71. Gjerdingen D, Katon W, Rich DE. Stepped care treatment of postpartum depression: a primary care-based management model. Womens Health Issues (2008) 18(1):44-52. doi:10.1016/j.whi.2007.09.001 
72. Gjerdingen DK, Yawn BP. Postpartum depression screening: importance, methods, barriers, and recommendations for practice. J Am Board Fam Med (2007) 20(3):280-8. doi:10.3122/jabfm.2007.03.060171

73. Fernandez y Garcia E, Joseph J, Wilson MD, Hinton L, Simon G, Ludman E, et al. Pediatric-based intervention to motivate mothers to seek follow-up for depression screens: the motivating our mothers (MOM) trial. Acad Pediatr (2015) 15(3):311-8. doi:10.1016/j.acap.2014.11.008

74. Yu Y, Liu ZW, Hu M, Liu HM, Yang JP, Zhou L, et al. Mental health helpseeking intentions and preferences of rural Chinese adults. PLoS One (2015) 10(11):e0141889. doi:10.1371/journal.pone.0141889

75. Mojtabai R, Evans-Lacko S, Schomerus G, Thornicroft G. Attitudes toward mental health help seeking as predictors of future help-seeking behavior and use of mental health treatments. Psychiatr Serv (2016) 67(6):650-7. doi:10.1176/appi.ps.201500164

76. Monti F, Agostini F, Marano G, Lupi F. The course of maternal depressive symptomatology during the first 18 months postpartum in an Italian sample. Arch Womens Ment Health (2008) 11(3):231-8. doi:10.1007/s00737-008-0017-6
77. Kothari C, Wiley J, Moe A, Liepman MR, Tareen RS, Curtis A. Maternal depression is not just a problem early on. Public Health (2016) 137:154-61. doi:10.1016/j.puhe.2016.01.003

78. Wisner KL, Perel JM, Peindl KS, Hanusa BH. Timing of depression recurrence in the first year after birth. J Affect Disord (2004) 78(3):249-52. doi:10.1016/ S0165-0327(02)00305-1

Conflict of Interest Statement: The authors declare that the research was conducted in the absence of any commercial or financial relationships that could be construed as a potential conflict of interest.

Copyright (c) 2017 Bauer, Ofner, Pottenger, Carroll and Downs. This is an open-access article distributed under the terms of the Creative Commons Attribution License (CC BY). The use, distribution or reproduction in other forums is permitted, provided the original author(s) or licensor are credited and that the original publication in this journal is cited, in accordance with accepted academic practice. No use, distribution or reproduction is permitted which does not comply with these terms. 